\title{
ENVIRONMENTAL PERCEPTIONS OF STUDENTS, FARMERS, AND OTHER ECONOMICALLY ACTIVE MEMBERS OF THE LOCAL POPULATION NEAR THE PROTECTED AREA OF AXIOS, LOUDIAS AND ALIAKMONAS ESTUARIES, IN GREECE
}

\author{
V. KLEFTOYANNI ${ }^{1}$ \\ G. ABAKOUMKIN ${ }^{2}$ \\ D. VOKOU ${ }^{1, *}$
}

Received: 21/09/09

Accepted: $13 / 04 / 10$

\author{
${ }^{1}$ Department of Ecology, School of Biology, \\ Aristotle University, GR-54124 Thessaloniki, Greece \\ ${ }^{2}$ Department of Preschool Education, University of Thessaly, \\ Argonafton \& Filellinon, GR-38221 Volos, Greece
}

*to whom all correspondence should be addressed: e-mail:vokou@bio.auth.gr

\begin{abstract}
This study concerns a protected area in northern Greece and examines how local people's occupation influences their perception of environmental impacts and their views and information about the area. The target groups were local residents that (a) were employed in the primary sector, (b) were employed in other economic sectors, and (c) were students or high-school seniors. Use of pesticides and fertilizers and industrial waste disposal were identified as sources of environmental impacts by the large majority of the total sample $(>80 \%)$. Much lower $(30-62 \%)$ was the perception of impacts from the other, more local stress sources. Primary-sector respondents (mostly farmers) scored lower in their environmental perceptivity; nevertheless, they were highly aware that some of their practices have negative impacts on the environment. Students outperformed the other groups in having visited the local information centre and in having attended an environmental information/ awareness event about the protected area; despite this, they also had the highest proportions of 'don't-know' answers. Small differences (even less than $5 \mathrm{~km}$ ) in the distance of respondents' residence from the protected area led to significant differences in environmental perceptivity. There is both a need for and interest from the local people to get better informed. As sufficient knowledge of the area and of the threats to its integrity is a requirement for the adoption and acceptance of measures aiming to moderate such threats, environmental information/ awareness events should be organized by the managing authorities. These should focus on issues specific to the area rather than of general environmental nature and target primarily people employed in the primary sector that live close to the protected area and students.
\end{abstract}

KEYWORDS: environmental education, environmental impacts, farmers, fertilizers, pesticides, waste.

\section{INTRODUCTION}

Several studies stress the importance of using local people's perceptions as an input for designing and applying appropriate management plans for sustainable development, particularly in protected areas (Agrawal, 2000; Newmark, et al. 1993; Papageorgiou and Vogiatzakis, 2006; Trakolis, 2001a,b). Ghimire and Pimbert (1997) regard such areas as social spaces that cannot be separated from their human context. Especially important in this regard are the perceptions of local people, who are in a special position to protect or undermine nearby protected areas depending on the decisions they make about the use of their own property, the activities they undertake, legally or illegally, and the degree to which they choose to oppose, support, or ignore the potentially destructive actions of others (Weaver and Lawton, 2008). Educational processes that increase environmental awareness and provide local communities with information about environmental issues, activities and decisions are a crucial key to success in protected-area management (Bauman and Smyth, 2007). 
The current work is part of a wider project aiming to explore rural people's knowledge and perceptions of environmental issues and their opinions about the effect of protection on the social and economic aspects of their life. It was conducted in the protected area of Axios-LoudiasAliakmonas estuaries, which is a large wetland area near Thessaloniki, the second biggest city of Greece. Protected areas face a combination of threats including pollution, over-exploitation, encroachment, poaching, and many others. Particularly those in proximity to major urban centers experience great difficulties in meeting their conservation objectives (Fortin and Gagnon, 1999; McNeely, 1994; Mitchell, 1994). This is even worse when they include estuaries. Being the intersection of land, river and sea, estuaries become very attractive for settlement, industry, harbours and trading (Blaber et al., 2000; Hoare, 2002). Accumulating by their nature sediments and chemicals, they can easily become polluted, which in turn will have negative impacts on human health and on the local flora and fauna.

Establishment of protected areas is associated with transitions in land-use patterns and entails regulations that control economic activities. This has a bearing on local life and is likely to have an effect on the images people create of their environment and of their own role in it. It is important, therefore, to understand the perceptions of the people that are first and foremost affected by conservation related regulations, i.e. those occupied in the primary sector. Students, on the other hand, are the most dynamic part of society and are those who will be the major future players. Local people employed in the other economic sectors may have direct access to new developments in the area, but, in general, they are little affected by conservation associated regulations; therefore, they can be considered as the control group with which current and future important social players are compared. In this work, we examine (i) whether the three groups are clearly distinct regarding their members' perception of environmental issues related with the protected area and (ii) how important are the environmental information/ awareness events for the three groups and how these enable the group members to have a better understanding of the features of the protected area and its problems.

\section{MATERIAL AND METHODS}

\subsection{The study area}

The study area is a major wetland area consisting of parts of the beds and of the estuaries of Axios (380 km long), Loudias (40 km), Aliakmonas (350 km) and Gallikos (65 km) rivers, of Kalohori lagoon, and of Kitros salt marsh. Loudias and Aliakmonas flow entirely in the Greek territory discharging into Thermaikos Gulf. Axios, one of the longest rivers of the Balkan Peninsula, has $90 \%$ of its watershed in FYROM (Former Yugoslav Republic of Macedonia). The area includes species and habitats protected after the Birds and Habitats Directives (Council Directive 79/409/EEC and 92/43/EEC, respectively). According to Maragou and Mantziou (2000), water purification and groundwater recharge are the major ecosystem services of this wetland.

The area was proclaimed protected in 2002 (3044/2002 in Government Gazette 197/27-8-2002) and its managing authority was first appointed in 2003 (126441/2469 in Government Gazette 918/B/4-72003). But its exact boundaries, zoning and measures for each zone became known only in mid2009, when the Common Ministerial Decision designating the area protected was published (12966/2009 in Government Gazette 220/D/14-5-2009). The protected area covers 33.800 ha; for its largest part, the highway connecting Thessaloniki with the capital Athens constitutes its upper border. An information centre is located in the Municipality of Halastra (Figure 1).

In the Special Environmental Assessment (MEPPPW, 1997), conducted in accordance with the provisions of the Greek Law 1650/1986 and the Common Ministerial Decision for designating protection status to an area (69269/5387/1990), as well as in a subsequent assessment made by the Organization of the Master Plan and Environmental Protection of Thessaloniki (OMPEPT, 2001), the use of pesticides and fertilizers, grazing, expansion of mussel farming, industrial waste disposal, sand extraction and poaching are identified as major factors impacting the area.

Rice culture yielding about 60\% (Karageorgis et al., 2005) and mussel farming yielding more than $85 \%$ (Alexandridis et al., 2008) of the total national production are the two major primary-sector activities in the area (MEPPPW, 1997). Up to now, there is no direct control for the maximum allowed quantity of fertilizers, pesticides or herbicides to be used in rice cultivation (Karageorgis et al., 2005); chemicals utilized in agriculture can have direct impacts on the wildfowl that uses rice fields as a habitat. Regarding mussel farming, a massive expansion took place in the 1990's in the 


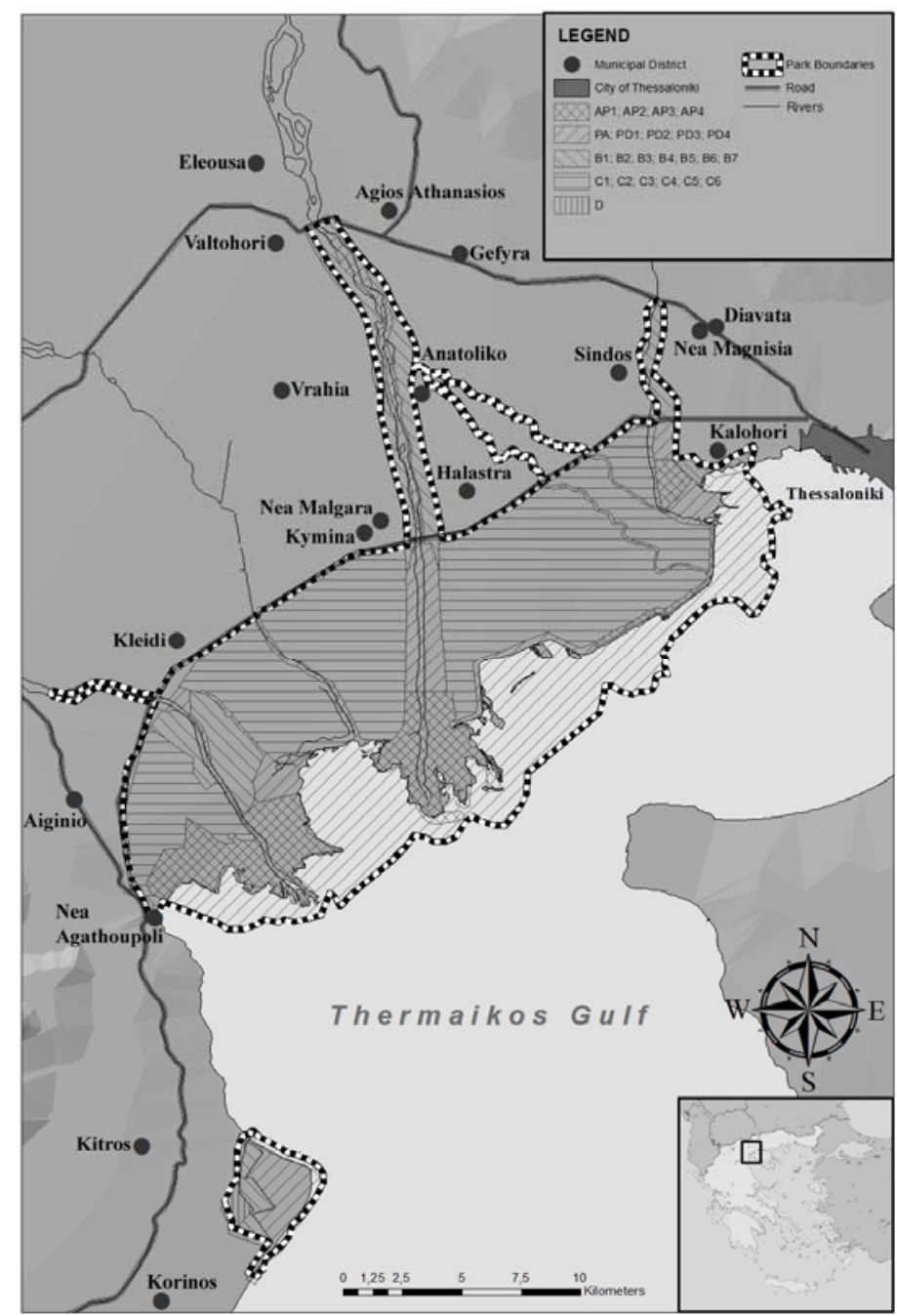

Figure 1. Map of the study area; marked are all municipal districts, where sampling took place, and the zones, into which the protected area is divided, corresponding to different levels of protection, from AP (absolute protection zone) to D (peripheral zone)

eutrophic Thermaikos Gulf. Resulting from inadequate control, this was accompanied by the establishment of illegal farms and auxiliary premises, by the accumulation of high amounts of solid waste (discarded cells and decaying biomass) that reduce the aesthetic value of the coastal zone and act as water current blockades that may cause toxic phytoplankton blooms (Nikolaidis et al., 2005) and by occasional outburst of severe hygienic problems (Karageorgis et al., 2005). Concerns about the potential impacts of mussel farming on the marine environment continue to increase along with discussions about the related issues of carrying capacity and sustainability (Alexandridis et al., 2008; Karageorgis et al., 2005; Moriki et al., 2008). Animal husbandry, primarily of cattle and sheep, impacts the wetland as several units that do not satisfy environmental and health criteria are still in operation. Waste disposal causes environmental damage, particularly because liquid wastes are often discharged untreated either from Greek or non-Greek sources. Loudias River, nowadays serving primarily for the drainage of the plain, is highly polluted, whereas Gallikos River has only seasonal waters. Because of inadequate control mechanisms resulting from hesitant endorsement of protection from the central and local authorities, a number of activities, not always conducted in legal ways, damage the environment; among these are hunting, banking earth and sand extraction.

In the 2001 census of the Statistical Service of Greece, 23,133 persons were registered economically active in the area and an almost equal number, 28,555, economically inactive (GSNSSG, 2001). Of those active, $24.9 \%$ were employed in the primary sector (agriculture, animal husbandry, forestry and fishing), $33.5 \%$ in manufacturing and constructions, whereas $16.1 \%$ were merchants; employment in any other public or private sector was less than $5 \%$. 


\subsection{Sampling}

The wetland area belongs administratively to three prefectures and 10 municipalities (Figure 1) that include 18 municipal districts. Quota sampling was used in order to have proportional representation of the local community. Every fifth person appearing in previously specified public places (square, cafeteria, etc.) that was a permanent resident of any of the 10 municipalities was asked to participate. The survey was carried out using a questionnaire that we administered in face-to-face interviews, always conducted by the same person, thus avoiding possible bias associated with different interviewers. Response rate was high (>80\%). Interviews lasted approximately 20 minutes each. Data collection took place from September to December 2006.

\subsection{Data collected and analysis}

We dealt with three major issues. The first concerned perception of sources of environmental stress. More specifically, we gave a list of identified stress factors to respondents and asked them if they believed that these factors had negative impacts on the area; these were (i) fertilizers, (ii) pesticides, (iii) sand extraction, (iv) industrial waste, (v), grazing, (vi) expansion of mussel culture, and (vii) hunting. By use of an open question, we additionally asked respondents to identify the main causes of river pollution in the area and also whether they believed that the quality of river water affects health. The second issue concerned their views regarding the naturalness of the protected area; we asked them if they wanted more paved roads in it and if they agreed for illegal constructions to be removed from it. The last issue concerned the knowledge they had of the existence of the managing authority and of the information centre, if they had ever visited the latter, if they had attended an environmental information/ awareness event about the protected area, and if they wanted to get better informed. For all questions in Table 2 about perceptions, and for the last question in Table 4 regarding respondents' willingness to become better informed, positive, negative, neutral or 'don't-know' answers could be given. For all other questions of Table 4, respondents could give only positive or negative answers. The answer to the corresponding question was considered positive if respondents had participated in any information/ awareness event about the protected area, from environmental education programs to short duration environmental information events. In data analysis and subsequent presentation of results, neutral and 'don't-know' answers were grouped together.

We recorded occupation, gender, age and education of respondents; the interview continued only if the respondent was older than 16 years of age. As several of the residents of this area have multiple occupations, we had to take decisions about where to group them. If respondents were high-school seniors or students, they were invariably classified to the student group, even if they had a parallel economic activity. If any of the activities of the non-student respondents fell within the primary sector, respondents were classified to this sector. All others, employed in manufacture and constructions, retail, education, insurance, banking, tourism, social services, etc, were grouped together. We also recorded the distance of the respondents' residence from the protected area; we always estimated it from the main part of the protected area, not from the narrow riverbeds that might be closer to the respondents' residence (see Figure 1).

To detect response variation among the three groups, we cross tabulated the variables and conducted chi-square tests of independence. We developed a compound index that takes into consideration the respondents' ability to recognize environmental stress sources and to connect river quality with health as well as preference for naturalness of the protected area; this represents the respondents' environmental perceptivity. For all topics presented in Table 2, except for that of paved roads, positive answers were scored with 3, 'don't-know or neutral' answers with 2 and negative ones with 1; for the 'paved roads' question the positive answer was scored with 1 and the negative with 3 . The average score gave the respective value of the environmental perceptivity index. A Cronbach's $a=0.64$ indicating acceptable reliability was estimated. The scores of this index were submitted to analysis of variance with occupation and distance of residence from the protected area as independent variables. All data analyses were carried out in Statistica 7.

\section{RESULTS}

\subsection{Respondents' profile}

The primary-sector group consisted of 249 interviewees, that of all other sectors of 219 , whereas 111 made the student group. Of the primary sector, 198 were farmers, of which 92 with no other activity; therefore, farmers made $80 \%$ of the primary-sector group. The great majority of 
respondents were men (Table 1). The age groups ' $21-40$ ' and '41-60' were fairly equally represented making together about $75 \%$ of the sample. About half of the respondents $(47 \%)$ had vocational training; those having only primary, secondary, or higher education corresponded each to $15-20 \%$ of the entire sample. Half of the respondents $(51 \%)$ resided very close to the protected area; the other half was rather equally divided between those residing at a distance of $1-5 \mathrm{~km}$ and above $5 \mathrm{~km}$. Chi-square test of independence revealed significant differences among the three groups for all four sample characteristics examined (Table 1).

Table 1. Proportion of respondents sharing common features and results of the cross tabulations of the sample features with occupation

\begin{tabular}{|c|c|c|c|c|c|}
\hline \multirow[b]{2}{*}{$\begin{array}{l}\text { Respondents' } \\
\text { features }\end{array}$} & \multirow{2}{*}{$\begin{array}{c}\text { Total } \\
\text { sample } \\
(\%)\end{array}$} & \multicolumn{3}{|c|}{ Occupation (\%) } & \multirow{2}{*}{$x^{2}$} \\
\hline & & $\begin{array}{l}\text { Primary } \\
\text { Sector }\end{array}$ & $\begin{array}{c}\text { Non-primary } \\
\text { sectors }\end{array}$ & Students & \\
\hline Gender & & & & & $120.8^{* * *}$ \\
\hline Women & 26.6 & 5.6 & 34.3 & 58.6 & \\
\hline Men & 73.4 & 94.4 & 65.7 & 41.4 & \\
\hline Age & & & & & $404.1^{* * *}$ \\
\hline$<21$ years old & 17.6 & 0.8 & 6.0 & 78.4 & \\
\hline 21 - 40 years old & 39.6 & 41.0 & 47.0 & 21.6 & \\
\hline $41-60$ years old & 34.7 & 40.2 & 46.1 & - & \\
\hline$>60$ years old & 8.1 & 18.0 & 0.9 & - & \\
\hline Education & & & & & $129.4^{* * *}$ \\
\hline Primary & 20.2 & 35.7 & 12.8 & - & \\
\hline Secondary & 15.2 & 20.1 & 17.4 & - & \\
\hline Vocational training & 47.1 & 37.0 & 50.0 & 64.0 & \\
\hline Higher Education & 17.5 & 7.2 & 19.8 & 36.0 & \\
\hline $\begin{array}{l}\text { Residence distance } \\
\text { from the protected area }\end{array}$ & & & & & $12.7^{*}$ \\
\hline$<1 \mathrm{~km}$ & 51.1 & 53.4 & 50.7 & 46.9 & \\
\hline $1-5 \mathrm{~km}$ & 23.8 & 26.1 & 17.8 & 30.6 & \\
\hline$>5 \mathrm{~km}$ & 25.2 & 20.5 & 31.5 & 22.5 & \\
\hline
\end{tabular}

\subsection{Perceptions and views}

An overwhelming majority $(>80 \%)$ of the sample perceived negative effects on the natural environment from industrial waste disposal and use of pesticides and fertilizers (Table 2). Much fewer (30-62\%) were those perceiving negative impacts from the other activities. The majority of respondents $(57 \%)$ wanted more paved roads and a high proportion $(43 \%)$ wanted illegal buildings to be removed; but, in either case, more than a third of respondents had exactly the opposite views. In their large majority $(80 \%)$, they connected human health with river water quality.

Cross tabulating responses with occupation showed differences in all but one case: no difference was detected among groups for industrial waste disposal. Proportionally more respondents from the primary-sector did not perceive negative impacts. Students gave the fewest 'no impact' answers; but they also had the highest proportion of neutral/'don't-know' answers for five of the seven stress sources examined. Perception of stress sources was highest for the group of those employed in sectors other than the primary; only for hunting, students were the ones perceiving stresses to a larger extent. More than $10 \%$ of those employed in the primary sector did not answer with a clear 'yes' or 'no' to the question whether fertilizers and pesticides had environmental impacts. Illegal constructions and paved roads had most of their advocates among respondents of the primary sector. The least support for paved roads was expressed by students, whereas for illegal buildings 
Table 2. Recognition of negative impacts on the protected area from seven pre-specified factors, responses related to its naturalness and river water quality, and results of the cross tabulations with occupation

\begin{tabular}{|c|c|c|c|c|c|c|}
\hline \multirow[b]{2}{*}{ Questions } & \multirow[b]{2}{*}{ Answers } & \multirow{2}{*}{$\begin{array}{l}\text { Total } \\
\text { sample } \\
(\%)\end{array}$} & \multicolumn{3}{|c|}{ Occupation (\%) } & \multirow[b]{2}{*}{$x^{2}$} \\
\hline & & & $\begin{array}{l}\text { Primary } \\
\text { Sector }\end{array}$ & $\begin{array}{l}\text { Non-primary } \\
\text { sectors }\end{array}$ & Students ${ }^{1}$ & \\
\hline \multicolumn{7}{|l|}{$\begin{array}{l}\text { Do you believe that the } \\
\text { following factors are sources } \\
\text { of environmental damage? }\end{array}$} \\
\hline \multirow[t]{2}{*}{ Use of fertilizers } & $\begin{array}{l}\text { Yes } \\
\text { No }\end{array}$ & $\begin{array}{c}83.9 \\
8.1\end{array}$ & $\begin{array}{l}75.1 \\
13.7\end{array}$ & $\begin{array}{c}91.3 \\
4.1\end{array}$ & $\begin{array}{l}89.2 \\
3.6\end{array}$ & $27.27^{\star * *}$ \\
\hline & $\begin{array}{l}\text { Neutral/ } \\
\text { No opinion }\end{array}$ & 7.9 & 11.2 & 4.6 & 7.2 & \\
\hline \multirow[t]{2}{*}{ Use of pesticides } & $\begin{array}{l}\text { Yes } \\
\text { No }\end{array}$ & $\begin{array}{c}89.8 \\
3.8\end{array}$ & $\begin{array}{c}82.7 \\
6.8\end{array}$ & $\begin{array}{c}95.0 \\
1.8\end{array}$ & $\begin{array}{l}95.5 \\
0.9\end{array}$ & $24.39^{* \star *}$ \\
\hline & $\begin{array}{c}\text { Neutral/ } \\
\text { No opinion }\end{array}$ & 6.4 & 10.4 & 3.2 & 3.6 & \\
\hline \multirow[t]{2}{*}{ Grazing } & $\begin{array}{l}\text { Yes } \\
\text { No }\end{array}$ & $\begin{array}{l}32.8 \\
53.0\end{array}$ & $\begin{array}{l}24.5 \\
65.1\end{array}$ & $\begin{array}{l}40.2 \\
48.9\end{array}$ & $\begin{array}{l}36.9 \\
34.3\end{array}$ & $45.24^{* * *}$ \\
\hline & $\begin{array}{l}\text { Neutral/ } \\
\text { No opinion }\end{array}$ & 14.2 & 10.4 & 11.0 & 28.8 & \\
\hline \multirow[t]{2}{*}{ Expanding mussel culture } & $\begin{array}{l}\text { Yes } \\
\text { No }\end{array}$ & $\begin{array}{l}30.1 \\
25.9\end{array}$ & $\begin{array}{l}29.3 \\
30.1\end{array}$ & $\begin{array}{l}31.5 \\
26.5\end{array}$ & $\begin{array}{l}28.8 \\
15.3\end{array}$ & $11.2^{*}$ \\
\hline & $\begin{array}{l}\text { Neutral/ } \\
\text { No opinion }\end{array}$ & 44.0 & 40.6 & 42.0 & 55.9 & \\
\hline \multirow[t]{2}{*}{ Industrial waste disposal } & $\begin{array}{l}\text { Yes } \\
\text { No }\end{array}$ & $\begin{array}{c}95.0 \\
1.7\end{array}$ & $\begin{array}{l}94.8 \\
2.4\end{array}$ & $\begin{array}{c}95.9 \\
1.4\end{array}$ & $\begin{array}{c}93.7 \\
0.9\end{array}$ & $3.2 \mathrm{NS}$ \\
\hline & $\begin{array}{l}\text { Neutral/ } \\
\text { No opinion }\end{array}$ & 3.3 & 2.8 & 2.7 & 5.4 & \\
\hline \multirow[t]{2}{*}{ Hunting } & $\begin{array}{l}\text { Yes } \\
\text { No }\end{array}$ & $\begin{array}{l}61.7 \\
18.6\end{array}$ & $\begin{array}{l}53.8 \\
25.8\end{array}$ & $\begin{array}{l}65.8 \\
16.4\end{array}$ & $\begin{array}{c}71.2 \\
7.2\end{array}$ & $20.4^{\star * *}$ \\
\hline & $\begin{array}{l}\text { Neutral/ } \\
\text { No opinion }\end{array}$ & 19.7 & 20.4 & 17.8 & 21.6 & \\
\hline \multirow[t]{2}{*}{ Sand extraction } & Yes & 43.0 & 39.8 & 56.2 & 24.3 & $67.08^{* * *}$ \\
\hline & $\begin{array}{l}\text { Neutral/ } \\
\text { No opinion }\end{array}$ & 39.0 & 32.1 & 33.8 & 64.9 & \\
\hline \multirow{2}{*}{$\begin{array}{l}\text { Do you want the illegal } \\
\text { buildings to be removed? }\end{array}$} & Yes & $\begin{array}{l}42.8 \\
339\end{array}$ & 39.0 & $\begin{array}{l}50.7 \\
287\end{array}$ & $\begin{array}{l}36.0 \\
298\end{array}$ & $17.41^{* *}$ \\
\hline & $\begin{array}{l}\text { Neutral/ } \\
\text { No opinion }\end{array}$ & 23.3 & 20.9 & 20.6 & 34.2 & \\
\hline \multirow{2}{*}{$\begin{array}{l}\text { Do you want more paved } \\
\text { roads in the protected area? }\end{array}$} & Yes & 57.6 & $\begin{array}{l}70.3 \\
25.7\end{array}$ & 49.7 & $\begin{array}{l}45.1 \\
43 ?\end{array}$ & $30.52^{\star \star *}$ \\
\hline & $\begin{array}{l}\text { Neutral/ } \\
\text { No opinion }\end{array}$ & 7.3 & 4.0 & 8.7 & 11.7 & \\
\hline \multirow{2}{*}{$\begin{array}{l}\text { Do you believe that the river } \\
\text { water quality is connected to } \\
\text { health? }\end{array}$} & $\begin{array}{l}\text { Yes } \\
\text { No }\end{array}$ & $\begin{array}{l}79.8 \\
10.7\end{array}$ & $\begin{array}{l}73.5 \\
16.9\end{array}$ & $\begin{array}{c}86.3 \\
5.5\end{array}$ & $\begin{array}{c}81.1 \\
7.2\end{array}$ & $19.06^{\star \star *}$ \\
\hline & $\begin{array}{c}\text { Neutral/ } \\
\text { No opinion }\end{array}$ & 9.5 & 9.6 & 8.2 & 11.7 & \\
\hline
\end{tabular}


by those employed in the non-primary sectors. A rather high proportion of respondents from the primary sector $(17 \%)$ did not believe that the quality of the river water and health are connected.

In the open question about the main causes of river pollution in the area, $5 \%$ of the sample had nothing to contribute. Industry was identified as the main cause by a large majority (64\%) with specific industrial plants being named by $11 \%$ of the respondents. Agriculture followed $(32 \%)$, but the corresponding proportion was half that for industry (Figure 2); pesticides outscored fertilizers as a cause of river pollution ( $28 \%$ and $13 \%$, respectively). Waste disposal was mentioned by $12 \%$ of the sample, whereas solid waste by $7 \%$. Very few respondents identified fishing or animal breeding activities, whereas $13 \%$ identified river pollution sources outside the Greek territory. Analysis of the most frequently mentioned causes of river pollution with occupation (Table 3) showed significant among-group differences for all causes except for industry. Respondents working in the primary sector identified agriculture less and non-Greek sources more as sources of river pollution than did the members of the other groups. Solid waste was identified as a main source mainly by students.

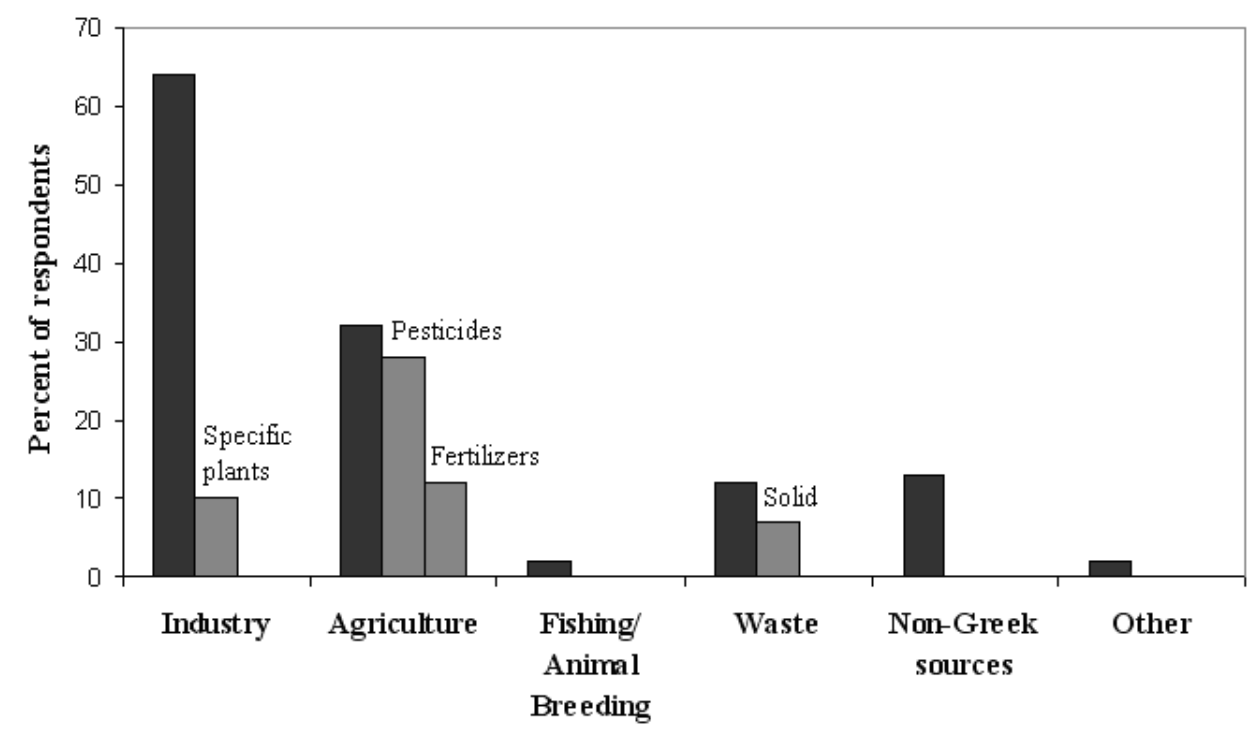

Figure 2. Sources of river pollution, as identified by respondents; grey columns correspond to more precisely defined sources within each category

Table 3. Results of the cross tabulations of the most frequently mentioned causes of river pollution with occupation

\begin{tabular}{lccccc}
\hline \multirow{2}{*}{$\begin{array}{l}\text { Sources of river } \\
\text { pollution }\end{array}$} & $\begin{array}{c}\text { Total } \\
\text { sample }\end{array}$ & \multicolumn{4}{c}{ Occupation (\%) } \\
\cline { 3 - 5 } & $(\%)$ & $\begin{array}{c}\text { Primary } \\
\text { Sector }\end{array}$ & $\begin{array}{c}\text { Non-primary } \\
\text { sectors }\end{array}$ & Students ${ }^{1} n$ & $x^{2}$ \\
\hline Industry & 68 & 70.8 & 68.1 & 59.6 & $4.15 \mathrm{NS}$ \\
Agriculture & 34 & 27.5 & 39.4 & 33.7 & $7.19^{*}$ \\
Non-Greek sources & 13 & 19.3 & 11.7 & 2.9 & $17.57^{* * *}$ \\
Solid Waste & 8 & 3.9 & 9.4 & 13.5 & $10.38^{* *}$ \\
\hline${ }^{* * *}=p<0.001,{ }^{* *}=p<0.01,{ }^{*}=p<0.05$, NS $=$ non significant & & \\
${ }^{1}$ including high school seniors $>16$ years old & & &
\end{tabular}

Analysis of variance of the environmental perceptivity scores (Figure 3) with occupation and distance of the respondents' residence from the protected area (less than $1 \mathrm{~km}$ vs. $1-5 \mathrm{~km}$ vs. more than $5 \mathrm{~km})$ as factors yielded a main effect of occupation $[F(2,570)=25.11, p<0.01]$ and a main effect of distance $[F(2,570)=5.64, p<0.01]$; their interaction was not significant $[F(4,570)=1.18]$. Simple main effects analysis showed that respondents from the primary sector scored lower $(M=$ $2.24, S D=0.35)$ than those from the other sectors $(M=2.46, S D=0.33)$ and the students $(M=$ $2.45, S D=0.29$ ); the latter groups did not differ from each other (Figure 3a). Regarding the distance main effect, this was due to the difference between residents living closest $(M=2.32, S D=0.34)$ and residents living away from the protected area $(M=2.46, S D=0.35)$; those living near scored lower (Figure 3b), whereas those in mid-distance did not differ from either of the other two groups $(M=2.36, S D=0.36)$. Entering education as a covariate did not affect considerably the pattern of 
results, although education covaried with environmental perceptivity $[F(1,568)=21.90, p<0.01]$; the higher the education the higher the environmental perceptivity.
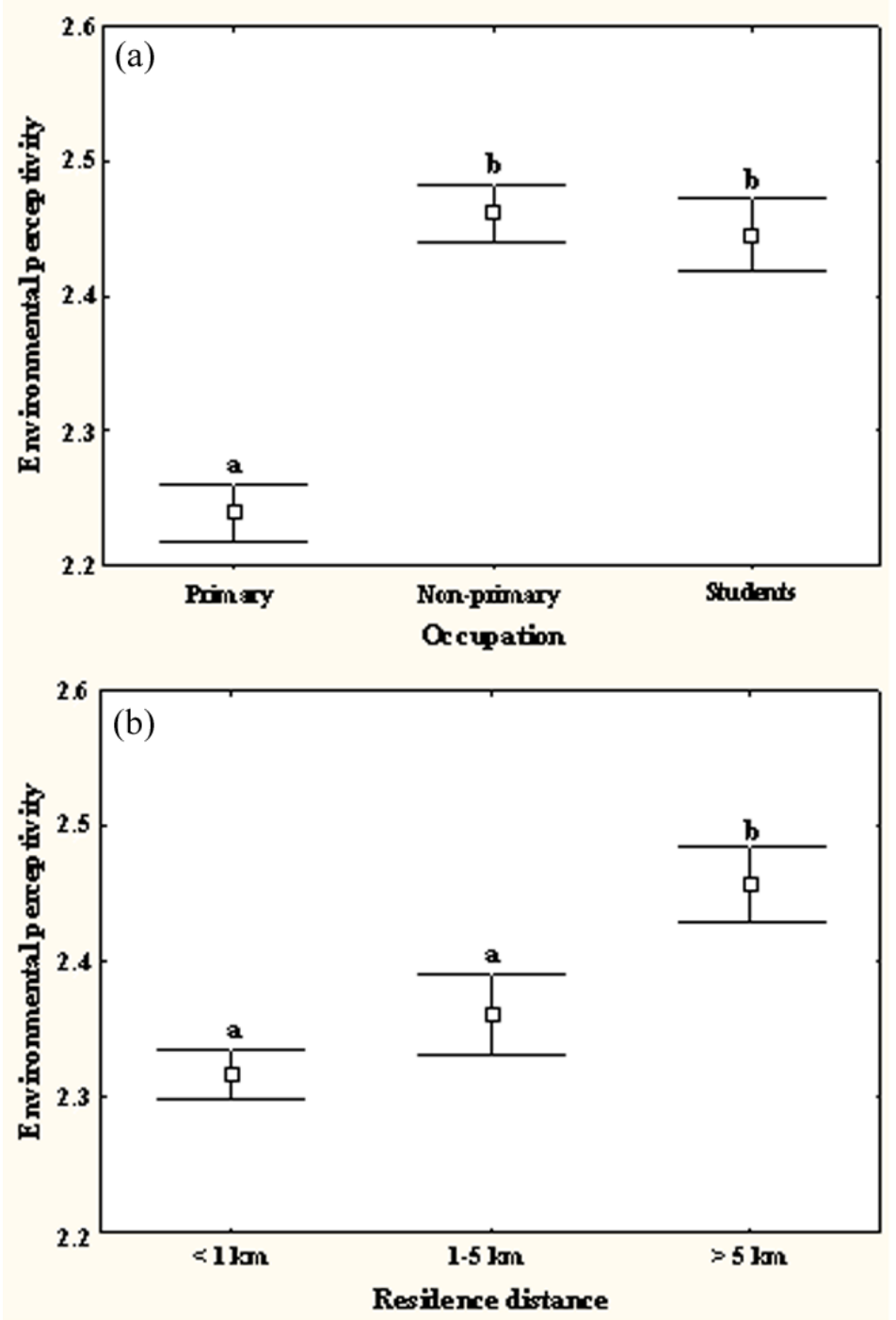

Figure 3. Environmental perceptivity (mean \pm s.e.) of respondents as a function of their occupation

(a) and the distance of their residence from the protected area (b);

letters above values indicate significant differences, at $p<0.01$

(for definition of environmental perceptivity see Material and Methods)

\subsection{Information}

A little more than a quarter of the sample attended an environmental information/ awareness event about the protected area (Table 4). Similar was the proportion of those knowing of the operation of the information centre, but far less $(16 \%)$ knew of the existence of the managing authority that runs it. The three groups did not differ in their knowledge of the information centre, but differed markedly in having visited it. Of those aware of its existence, the large majority of students $(78 \%)$ and a high proportion of those employed in sectors other than the primary $(61 \%)$, but only $28 \%$ of the primarysector respondents had visited it. The three groups differed regarding their participation in environmental information/ awareness events and their knowledge of the existence of the managing authority. In both cases, students diverged markedly from the other two groups; very few knew of the managing authority $(6.3 \%)$ but outperformed the other groups in having attended an environmental event about the protected area $(39.6 \%$ vs. 18.5 and 22.8 , for the respondents of the primary and non-primary sectors, respectively). The large majority of respondents (79\%) wanted to be further informed; only $8 \%$ clearly stated that they were not interested in getting more information on the protected area. 
Table 4. Answers to questions regarding respondents' knowledge of the managing authority and its activities and results of the cross tabulations with occupation

\begin{tabular}{|c|c|c|c|c|c|c|}
\hline \multirow[b]{2}{*}{ Questions } & \multirow{2}{*}{ Answers } & \multirow{2}{*}{$\begin{array}{c}\text { Total } \\
\text { sample } \\
(\%)\end{array}$} & \multicolumn{3}{|c|}{ Occupation (\%) } & \multirow[b]{2}{*}{$x^{2}$} \\
\hline & & & $\begin{array}{l}\text { Primary } \\
\text { Sector }\end{array}$ & $\begin{array}{c}\text { Non-primary } \\
\text { sectors }\end{array}$ & Students ${ }^{1}$ & \\
\hline $\begin{array}{l}\text { Do you know that there } \\
\text { exists a managing } \\
\text { authority of the protected } \\
\text { area? }\end{array}$ & Yes & 16.4 & 18.9 & 18.7 & 6.3 & $10.22^{* *}$ \\
\hline $\begin{array}{l}\text { Do you know that an } \\
\text { information center } \\
\text { operates in the area? }\end{array}$ & Yes & 26.7 & 28.9 & 26.0 & 25.2 & $0.74 \mathrm{NS}$ \\
\hline If so, have you visited it? & Yes & 55.8 & 28.2 & 61.4 & 77.8 & $24.78^{* * *}$ \\
\hline $\begin{array}{l}\text { Have you attended any } \\
\text { information/ awareness } \\
\text { event about the protected } \\
\text { area? }\end{array}$ & Yes & 27.0 & 18.5 & 22.8 & 39.6 & $19.11^{* * *}$ \\
\hline \multirow{3}{*}{$\begin{array}{l}\text { Would you like to be } \\
\text { further informed about the } \\
\text { protected area? }^{2}\end{array}$} & Yes & 79.3 & 83.7 & 82.6 & 71.6 & $19.78^{* * *}$ \\
\hline & Neutral & 13.0 & 6.5 & 10.5 & 22.0 & \\
\hline & No & 7.7 & 9.8 & 6.9 & 6.4 & \\
\hline
\end{tabular}

${ }^{* * *}=$ significant at $p<0.001,{ }^{* *}=$ at $p<0.01,{ }^{*}=$ at $p<0.05, \mathrm{NS}=$ non significant

1 including high school seniors $>16$ years old

2 for this question, there were three types of answers, for the other questions of the table, there were only yes or no answers

\section{DISCUSSION}

Social groups are reported to perceive issues in relation to their own interests and needs (Wallner et al., 2007). For instance, Lian et al. (2007) reported that $45 \%$ of the Chinese farmers that were interviewed do not recognize environmental impacts of their agriculture practices. In another study, in which farmers were asked to evaluate sources of water pollution, they hold industry and household responsible for water pollution, while minimizing the impacts of their own harmful practices (Michel-Guilloua and Moserb, 2006). This was also the case in our study. In addition, compared to the members of the other groups, primary-sector respondents scored less in questions about the recognition of sources of negative impacts and in connecting river water quality with health, but more in attributing river pollution to external factors beyond the borders of the country. Only for the contribution of industry to river pollution was there a general consensus. It is also worth noting that the members of the primary-sector group also failed to perceive impacts from other sources to a higher degree than the members of the other two groups. As protected areas like the study area are often promoted by remote authorities, local people often see them as an unwanted intrusion into their daily use of natural resources and are likely to be negatively disposed towards their establishment (Ghimire and Pimbert, 1997; West and Brechin, 1991); in a relevant study, Harisson et al. (1998) found that farmers challenge the monopoly of knowledge conservationist profess about nature. On the other hand, stakeholders are not always aware or underestimate the importance of risk factors (Loubier et al., 2005). Whether our findings suggest underestimation of environmental threats or are a sign of negative attitude to the protection status and the associated restrictions cannot be answered with the type of research we did and needs to be further explored. Nevertheless, a closer look at the results obtained shows that the deviation of the primary-sector respondents from the other two groups was constant but not striking. It is also noteworthy that for factors associated with the farmers' activities, as is the use of pesticides and fertilizers, the great majority of primary-sector respondents did perceive negative impacts, $83 \%$ and $75 \%$, respectively. Though lower than of the other two groups, these proportions are still very high. They are also higher than the respective ones reported for Chinese farmers in response to questions about the environmental impacts of their agricultural practices (55\%) (Lian et al., 2007) or for the general 
public in Scotland regarding perception of impacts of pesticides, fertilizers and chemical sprays on land $(70 \%)$ (Wilkinson and Waterton, 1991), or for the general public in the UK regarding damages to the environment caused by chemicals (75\%) (Knight, 1998).

To examine whether the composition of the group introduced a bias to our results, we examined separately farmers that had no other occupation (92 respondents). Comparing their answers to those of the whole primary-sector group (Table 2), we found considerable differences, of more than five units, only in three cases: (i) for the use of fertilizers, (ii) for the use of pesticides, and (iii) for the expansion of mussel culture. More specifically, $66.3 \%$ of strictly farmers as opposed to $75.1 \%$ of the whole primary-sector group, $73.9 \%$ as opposed to $82.7 \%$, and $22.8 \%$ as opposed to $29.3 \%$ perceived (i), (ii) and (iii), respectively, as sources of environmental damage. This shows that the large majority of farmers are quite aware of the environmental impacts of their practices on the area. Given that less than $20 \%$ attended an environmental information/ awareness event, this seems to reflect a generally high public awareness on such issues (Dunlap, 1991) attained by other, more general means.

Half the sample did not recognize negative impacts from grazing and more than a third had no opinion or neutral views for the environmental impacts of sand extraction and mussel culture. As we asked respondents to only point the sources of negative impacts, not rank them, these results suggest that local people do not have a clear picture of the factors that shape their environment and that in a number of cases their views deviate from those of the scientists involved in the assessment of the area. This indicates the need for more focused actions that will increase the knowledge base of local people. Sufficient knowledge of the area and of the current and potential threats to its integrity is a requirement both for the adoption and for the acceptance of measures aiming to moderate such threats. Yet, management decisions may still fail to win public approval because important threats can be perceived differently by stakeholders (Kerns and Ager, 2007). Involvement of main stakeholders in threat assessment can help attenuate this problem and provide opportunities to communicate information, which can influence public perceptions and attitudes (Kerns and Ager, 2007).

More people from all groups knew of the existence of the information centre than of the managing authority. This may reflect the fact that the centre operated under a different scheme before the managing authority appeared in the area. But it may equally reflect the fact that the managing authority has not made its presence and activities visible, so far.

There are reports of drastic changes in people's perceptions and attitudes with low-scale spatial differences. For instance, Jim and Xu (2002) asked local people in Shimentai Nature Reserve, in South China, if they expected that their household would suffer from the reserve-associated regulations. A significant difference in the loss expectations was found between near- and far-zone villagers; far-zone residents overwhelmingly expected no loss $(90.1 \%)$, contrasted by near-zone ones, who overwhelmingly expected some losses (92.2\%). Though significant, the differences between near- and far-residents in our study area were not as dramatic.

Education is critical for promoting sustainable development as it can shape people's perceptions and improve their attitudes (Jim and Xu, 2002; Newmark et al., 1993; Xu et al., 2006). Hager et al. (2007) found high-school seniors to have a high level of concern for the environment. Similarly, in the Axios, Loudias, and Aliakmonas area, the group of high school seniors and students scored high in their perception of sources of environmental stress and in their support for the naturalness of the area. At the same time, although they outperformed the other groups in having visited the information centre and in having attended an environmental information/ awareness event about the protected area, their 'do-not-know' or neutral answers were even double the corresponding ones for the other groups regarding stress sources of mainly local interest (such as sand extraction or expanding mussel culture). Surveys of secondary school students in several countries report generally low levels of factual knowledge related to environmental issues and that the knowledge levels can vary considerably among different topics (Rickinson, 2001). Regarding perception of environmental threats, Battisti et al. (2008) reported that students may consider as serious some categories of threats that are general and popularly invoked in mass media as dangers for the environment and the natural ecosystems (such as pollution) and underestimate unpopular local threats. This seems to be the case for the students in our study and to a minor degree for the other groups. But this also indicates the need for adopting learning situations and processes that can enable people to better perceive and understand the scientific and socio-political aspects of 
environmental issues (Rickinson, 2001). The managing authority could greatly benefit from the development and implementation of well-focused and target-specific environmental information/ awareness events.

Finally, apart from expressing group-specific perceptions, results of this study reflect primarily the way that the male part of the local society perceives environmental issues. This is due to the malebiased structure of our sample $(73.4 \%$ male), which is predominantly the result of the unbalanced gender composition of the primary-sector group. This can be amended in future studies by focusing on the female part of the local society.

\section{CONCLUSION}

The three groups differed in their views on issues related to the protected area, their perception of sources of environmental impacts and the information they had and were willing to have. The most widely-held perceptions were that use of pesticides and fertilizers and industrial waste disposal are threats to the local environment; other threat sources were hardly recognized. Apart from occupation, education and location of respondents' residence influenced their responses to the issues dealt with. We conclude that despite their differences, the three groups did not diverge dramatically from each other, something that suggests a rather coherent local society. But, there is both a need for and interest from the local people to get better informed about the protected area. Environmental information/ awareness events focused on issues specific to the area rather than of general environmental nature and targeting specific groups could be an answer to this. Drawing on the findings of this study, the priority focus groups are people employed in the primary sector that live close to the protected area ( $<5 \mathrm{~km}$ from it) and students. Managing authorities should use the opportunity of such events to connect with the public, use the local knowledge and build on it, and clearly communicate goals, priorities, and achievements in their efforts to strengthen public support and make possible public acceptance of the measures required to maintain the integrity of the area.

\section{ACKNOWLEDGEMENTS}

This research is co-financed by the EU-European Social Fund $(75 \%)$ and the Greek Ministry of Development-GSRT (03ED) (25\%). We thank the Board of the Managing Authority and the personnel of the protected area, particularly S. Vareltzidou and A. Gakis for their support and help.

\section{REFERENCES}

Agrawal A. (2000), Adaptive management in transboundary protected areas: the Bialowieza National Park and Biosphere Reserve as case study, Environ Conserv, 27, 326-333.

Alexandridis T.K., Topaloglou C.A., Lazaridou E. and Zalidis GC. (2008), The performance of satellite images in mapping aquacultures, Ocean Coast Manag, 51, 638-644.

Bauman T. and Smyth D. (2007), Indigenous partnerships in protected area management in Australia: three case studies, Australian Institute of Aboriginal and Torres Strait Islander Studies and The Australian Collaboration.

Battisti C., Luiselli L., Pantano D., Teofili C. (2008), On threats analysis approach applied to a Mediterranean remnant wetland: Is the assessment of human-induced threats related to different level of expertise of respondents? Biodivers Conserv 17, 1529-1542.

Blaber S., Cyrus D., Albaret J.J., Ching C., Day J., Elliott M., Fonseca M., Hoss D., Orensanz J., Potter I. and Silvert W. (2000), Effects of fishing on the structure and functioning of estuarine and nearshore ecosystems, ICES J Mar Sci, 57, 590-602.

Dunlap R.E. (1991), Trends in public opinion toward environmental issues 1965-1990, Soc Nat Resour, 4, 285-312.

Fortin M.J. and Gagnon C. (1999), An assessment of social impacts of national parks on communities in Quebec, Canada, Environ Conserv, 23, 200-211.

Ghimire K. and Pimbert M. (1997), Social change and conservation: an overview of issues and concepts. In: Social change and conservation, Ghimire K. and Pimbert M.P. (Eds.), Earthscan, London.

General Secretariat of National Statistical Service of Greece (GSNSSG) (2001) Census of Population 2001 (http://www.statistics.gr).

Hager S., Straka T. and Irwin H. (2007), What do teenagers think of environmental issues and natural resources management careers?, J For, 105, 95-98.

Harrison C.M., Burgess J. and Clark J. (1998), Discounted knowledges: farmers' and residents' understandings of nature conservation goals and policies, J Environ Manag, 54, 305-320. 
Hoare A. (2002), Natural harmony but divided loyalties: the evolution of estuary management as exemplified by the Severn estuary, Appl Geogr, 22, 1-25.

Jim C.Y. and Xu S.S.W. (2002), Stifled stakeholders and subdued participation: interpreting local responses toward Shimentai Nature Reserve in South China, Environ Manag, 30, 327-341.

Karageorgis A.P., Skourtos M.S., Kapsimalis V., Kontogianni A.D., Skoulikidis N.Th., Pagou K., Nikolaidis N.P., Drakopoulou P., Zanou B., Karamanos H., Levkov Z. and Anagnostou Ch. (2005), An integrated approach to watershed management within the DPSIR framework: Axios River catchment and Thermaikos Gulf, Reg Environ Chang, 5, 138-160.

Kerns B.K. and Ager A. (2007), Risk assessment for biodiversity conservation planning in Pacific Northwest forests, For Ecol Manag, 246, 38-44.

Knight R. (1998), Public opinion - Chemicals come under question, Eur Chem News Suppl, 6-8.

Lian G., Guo X.D., Fu B.J., Wang J. and He T. (2007), Farmer's perception and response towards land policy and eco-environment based on participatory rural appraisal: A case study in the Loess hilly area, China, Int J Sustain Dev World, 14, 182-191.

Loubier S., Rinaudo J.D., Garin P., Boutet A. (2005), Preparing public participation at the catchment level: comparison of three methodologies applied to the Herault river basin, Water Sci Technol, $\mathbf{5 2}$, 33-41.

Maragou P. and Mantziou D. (2000), Assessment of the Greek Ramsar Wetlands, WWF, Athens.

Mc-Neely J.N. (1994), Protected areas for the 21st century: working to provide benefits to society, Biodivers Conserv, 3, 390-405.

Ministry for the Environment, Planning and Public Works, General Directorate of Environment, Department of Environmental Management (MEPPW) (1997), Programme for the mitigation of special environmental problems and a system for the operation and management of the protected area at the estuaries of the rivers Gallikos, Axios, Loudias and Aliakmonas, the Kitros saltworks, the Kalochori lagoon and their wider area. Phase A', Summary (in Greek).

Michel-Guilloua E. and Moserb G. (2006), Commitment of farmers to environmental protection: from social pressure to environmental conscience, J Environ Psychol, 26, 227-235.

Mitchell J.G. (1994), Our National Parks. Legacy at Risk, Natl Geogr Mag, 186, $20-55$.

Moriki A., Galinou-Mitsoudi S., Petridis D., Kosti D., Savvidis Y., Dimitriadis X., Newmark W.D., Leonard N.L., Sariko H.I. and Gamassa D.M. (1993), Conservation attitudes of local people living adjacent to five protected areas in Tanzania, Biol Conserv, 63, 177-183.

Nikolaidis G., Koukaras K., Aligizaki K., Heracleous A., Kalopesa E. and Moschandreou K. (2005), Harmful microalgal episodes in Greek coastal waters, J Biol Res, 3, 77-85.

Organization of the Master Plan and Environmental Protection of Thessaloniki (OMPEPT) (2001), Inventory of projects and studies and formulation of proposals for the restoration of natural and agricultural ecosystems situated in the west part of Thessaloniki coastal zone, Greek Biotope/Wetland Centre (EKBY) (in Greek).

Papageorgiou K. and Vogiatzakis I.N. (2006), Nature protection in Greece: an appraisal of the factors shaping integrative conservation and policy effectiveness, Environ Sci Policy, 9, 476-486.

Rickinson M. (2001), Learners and learning in Environmental education: A critical review of the evidence, Environ Edu Res, 7, 207-320.

Trakolis D. (2001a), Perceptions, preferences, and reactions of local inhabitants in Vikos-Aoos National Park, Greece, Environ Manag, 28, 665-676.

Trakolis D. (2001b), Local people's perceptions of planning and management issues in Prespes Lakes National Park, Greece, J Environ Manag, 61, 227-241.

Wallner A., Bauer N. and Hunziker M. (2007), Perceptions and evaluations of biosphere reserves by local residents in Switzerland and Ukraine, Landsc Urban Plan, 83, 104-114.

Weaver D.B. and Lawton L.J. (2008), Perceptions of a nearby exurban protected area in South Carolina, United States, Environ Manag, 41, 389-397.

West P.C. and Brechin S.R. (1991), National parks, protected areas and resident peoples: a comparative assessment and integration, In: Resident peoples and national parks, West P.C. and Brechin S.R. (Eds.), University of Arizona Press Tucson.

Wilkinson D. and Waterton J. (1991), Public attitudes to the environment in Scotland, Central Research Unit, Scottish Office, Edinburgh.

Xu J., Chen L., Lu Y. and Fu B. (2006), Local people's perceptions as decision support for protected area management in Wolong Biosphere Reserve, China, J Environ Manag, 78, 362-372. 